\title{
Integrated and Sustainable Benchmarking of Metro Rail System Using Analytic Hierarchy Process and Fuzzy Logic: A Case Study of Mumbai
}

\author{
Pradeep Chaitanya Jasti ${ }^{1,2} \cdot$ V. Vinayaka $\operatorname{Ram}^{1}$
}

Received: 24 January 2019/Revised: 22 June 2019/Accepted: 26 July 2019/Published online: 24 September 2019

(C) The Author(s) 2019

\begin{abstract}
Intra-city mobility affects the well-being of city dwellers and the quality of urban life. A highly sophisticated and sustainable mass rapid transit system is key to facilitating such mobility. Metro Rail is one such successful system suitable for Indian conditions. A network of around $425 \mathrm{~km}$ is under operation and about $700 \mathrm{~km}$ is under fast track implementation in various cities (MoHUA in Annual report 2017-2018, Government of India, 2018). On the other hand, Metro Rail is an expensive form of urban transport, so any non-viability can leave the public transit agencies and the government in huge debt towards repaying the loans with which the system has been funded. In this context, achieving viability and long-term sustainability becomes mandatory for metro systems; such viability can be achieved by thorough performance assessment and benchmarking of the system in conventional and sustainable dimensions. Though institutionalization of benchmarking is practiced globally, few such efforts have been attempted in India. This study attempts to develop a mode-specific benchmarking framework for metro systems, structuring nine performance indicators (criteria) and 34 evaluators (sub-criteria) with a case study of Mumbai. Multi-criteria decision making techniques such as the
\end{abstract}

Pradeep Chaitanya Jasti

jastipradeep@gmail.com

V. Vinayaka Ram

vinayak@hyderabad.bits-pilani.ac.in

1 Department of Civil Engineering, BITS Pilani, Hyderabad Campus, Shameerpet, Hyderabad 500 078, India

2 MMRCL, 3rd Floor, MMRCL Building, E-Block, BKC, Bandra East, Mumbai 400 051, India

Communicated by Xuesong Zhou. analytic hierarchy process and direct weighting are engaged to incorporate a priority-based weighting system into the benchmarking framework. As the performance is benchmarked against set targets (absolute benchmarking), vagueness associated with the scaling/ranking is addressed through the fuzzy logic approach. Finally, the rate of performance of the Mumbai Metro Rail system is determined as $75 \%$ with acceptable results in the service, quality and societal sectors, though much improvement is needed in the sector of multimodal integration.

Keywords Sustainable benchmarking · Public transportation - Metro rail system - Urban rail transit . Performance evaluation - Analytic hierarchy process . Expert opinion · Fuzzy logic

\section{Background and Study Objective}

Due to unprecedented urbanization, vehicular traffic has grown at an alarming rate with a compound annual growth rate (CAGR) of $94.40 \%$ for 2011-2016 [1] which has resulted in heavy congestion and low mobility, and has compromised safety and increased emissions. Adding to this, urban local bodies (ULB) and planning authorities are investing huge capital on road infrastructure to satisfy the growing travel needs of the urban population. In order to alleviate this situation with minimal infrastructure, encouraging the public towards a mass rapid transit system (MRTS) is the most promising option for meeting the travel demand while achieving long-term sustainability goals in the urban context. Amongst the available MRTS modes, Metro Rail is regarded as the most successful mode for India, due to its substantial passenger carrying capacity. 
However, facilitating Metro Rail alone may not address this deep-rooted problem. The associated challenges towards development of this system, such as heavy capital investment, construction in densely populated urban areas, cost over-runs and financial viability, must be considered. Since these Metro Rail projects in India are largely being funded by bilateral and multilateral funding agencies, any non-viability after the commencement of commercial operations would badly affect the loan repayment ability of the public transit agency (PTA) and the local governments. Hence, continuous performance monitoring with a standardized benchmarking framework is required towards achieving the long-term sustainability and financial viability of these systems. With an objective to implement such a monitoring system, an integrated and sustainable mode-specific benchmarking framework has been developed exclusively for Metro Rail systems in India with 34 evaluators nested under nine performance indicators (PI). The broader structure of the framework is inspired by various guidelines and assessment techniques published by research agencies such as the Transportation Research Board (TRB), European Commission and the National Centre for Transit Research (NCTR), along with global practices followed by various transit authorities. The framework was developed to capture and evaluate all possible attributes influencing the overall performance of the system.

Mumbai has the highest public transport (PT) share in the world, i.e. 78\% [2]; its existing sub-urban system with 376 route $\mathrm{km} \mathrm{[3]} \mathrm{is} \mathrm{densely} \mathrm{overcrowded} \mathrm{with} \mathrm{a} \mathrm{passenger}$ load of 16 pax/sqm [2] at a cost of about 9 accidents per day [4]. With such a daunting situation, Mumbai badly requires an alternate MRT system, i.e. Metro Rail, to alleviate this overcrowded scenario and to meet the travel demand by offering a comfortable and reliable travel to its citizens. Currently, the city has only $11.40 \mathrm{~km}$ of operational Metro Rail network in the form of Mumbai Metro Line 1 connecting the eastern and western suburbs [5] the rest of the network is still under construction. Thorough assessment and benchmarking of the existing operational system in the present scenario offers an opportunity to identify the lacunae in the current performance of the system and to take necessary corrective measures for upcoming network changes towards achieving long term sustainability and viability. This scenario has motivated the authors to select Mumbai as the study area. Exercising the developed framework on a city of this scale and magnitude offers an excellent opportunity to examine the soundness of the proposed framework.

\section{Development of Benchmarking Framework}

The integrated and sustainable benchmarking framework of the Metro Rail system was developed to carry out a thorough assessment, capturing all possible factors influencing the system's overall performance. The framework developed is also expected to act as an institutionalized framework for benchmarking the performance of Metro Rail systems of all Indian cities. Prior to the development of the framework, the authors studied the present scenario of benchmarking practices and guidelines adopted in India, the gist of which is presented below.

- The Ministry of Urban Development (MoUD) of the Government of India issued guidelines for service level benchmarking (SLB) of urban transport system [6], and the same has been exercised in six Indian cities [7]. We observed that the framework was biased towards Tier I cities without much focus on sustainability-based development.

- MoUD updated the National Urban Transport Policy2014 with a priority towards development of a sustainable public transport network [8].

- The Government of India has taken encouraging initiatives towards promoting the MRTS system such as $50 \%$ cost sharing towards preparation of detailed project reports, $20 \%$ financial assistance to the approved projects etc. [1].

Keeping in view the cost over runs and substantial funding required by Metro Rail projects, the Ministry of Housing and Urban Affairs (MoHUA) has recently released the Appraisal Guidelines for Metro Rail Project Proposals [9] prescribing the end-to-end procedure for obtaining funding under the Metro Rail Policy 2017 [10]. A brief outline of the procedure is presented below.

- A comprehensive mobility plan (CMP) must be prepared to understand the present situation of urban transport in the city.

- An Alternative Analysis must be carried out, evaluating the alternative modes and measures considered for addressing the transportation chaos in the cities.

- Rating of the alternatives is to be carried out through performance measures.

- Subsequently, the proposal shall be considered for funding only after substantiating the need for Metro Rail over other alternatives.

From this, it can be understood that the aspect of sustainable benchmarking is yet to be realized even on a macroscopic scale of Urban Transport, hence exercising such practices on the microscopic scale of a metro system is far off. Even the recently released appraisal guidelines 
[9] place only a limited emphasis on the aspects of sustainability and post-operational benchmarking, leaving further scope to develop them.

Subsequent to the study of Indian guidelines, a brief review of international practices was carried out; the broader structure of the proposed benchmarking framework was inspired by various guidelines and assessment techniques published by internationally acclaimed research and transit agencies. To mention a few:

- A Guidebook for Developing a Transit Performance Measurement System, Transit Cooperative Research Program (TCRP) Report 88 by TRB [11].

- Transit Capacity and Service Quality Manual, Third Edition, TCRP Report 165 by TRB [12].

- Benchmark Rankings for Transit Systems in the United States, National Centre for Transit Research (NCTR) [13].

In addition to these guidelines, the practices adopted by Paz et al. [14], Aletr [15], Balachandra and Reddy [16], Bickford [17], Buehler and Pucher [18], Bongardt et al. [19], Bruun and Vanderschuren [20], Fu and Xin [21], Martens [22], Kittelson and Associates [23], Eboli and Mazzulla [24], Jasti and Ram [25, 26], Mishra et al. [27], Sybil Derrible et al. [28], Litman [29, 30], etc. were also examined while developing the framework.

These guidelines and practices offer a broader vision of global standards; learnings and understandings from these were used to establish a comprehensive and practical framework suitable for Indian conditions. In this context, the specific contributions made in this study are:

- Development of a novel mode-specific benchmarking framework for metro systems, which was observed to be a unique improvement when compared with the prevailing benchmarking tools and processes.

- Independent application of MCDM and fuzzy logic techniques, which make the framework-based benchmarking process robust.

- The framework can act as a simplified decision-making tool for prioritizing the development schemes.

The evaluator-specific formulations were developed with a view toward the local policies, National Fire Protection Association (NFPA) [31] standards and Indian data forms for in-depth assessment.

\subsection{Target Assessment and Description}

The proposed/developed comprehensive framework consists of nine PIs (criteria) structured with 34 evaluators (sub-criteria). A brief description of each PI along with its target assessment is presented below.
- Metro System and Network The basic service attributes such as availability and connectivity are assessed. In addition, the soundness of the system is assessed via the Transit Service Index, which measures the travel time savings attributable to the metro system in comparison with personalized modes.

- System Capacity A well-established system must provide adequate passenger handling capacity to remain sustainable and viable. Aspects such as volume/capacity ratio, car capacity and ridership are assessed under this indicator group with a target of evaluating the design and operational capacities of the passenger carrying facilities.

- Station Element Capacity Passenger dispersal facilities such as escalators, elevators and stairways should be adequate to handle the station loading. Since assessment of all these facilities is a complex exercise, the total exit time from the platform by an average passenger is measured by commuting an end-to-end trip during morning and evening peaks. The total exit time from platform to street level is measured and then benchmarked in accordance to NFPA-130, 2017 [31]. The walking speed is maintained at par with the crowd so as to capture the actual duration.

- Comfort and Customer Service Metro System being a highly sophisticated form of PT, commuter opinion on the same is important towards understanding the public opinion. Further, the mean vehicle age is assessed under this indicator group in accordance with MoUD guidelines [32].

- Multimodal Integration (MMI) Plays a key role in overall success of any PT system and all the ingress/ egress facilities are assessed in this indicator group. The roads within the station vicinity are classified based on their significance, and the desirable quantum of facilities to meet the broader demand as understood from the commuter survey analysis is defined as a benchmark.

- Environmental Sustainability Metro Rail is intended as a green and eco-friendly mode of transport, so environmental sustainability plays a key role in defining the success of the system. Accordingly, reductions in emissions and fuel consumption are assessed preand post-operation of the system to define its sustainability and contribution towards improving the ambient environment.

- Economic Sustainability Economic sustainability of the Metro Rail system is treated as significant, and is given high priority in authorization of funds. Aspects such as out-of-pocket savings, economic benefits to the end user, mobility index and peak hour factor are assessed under this indicator group. 
- Financial Sustainability For developing nations like India, accountability and prioritization of funds plays a key role which is directly dependent on the financial viability of the project. The attributing evaluators such as equity support, loan repayment, financial efficiency, percentage escalation of total project completion cost and percentage of fare revenue are assessed under this indicator group.

- Social Sustainability Success of any PT system is generally measured in terms of societal, rather than financial benefits. Hence, the aspects such as mode shift, property value impact, service equity to the enduser and access to differently abled passengers are assessed under this indicator group.

\subsection{The Proposed Framework for Benchmarking}

The mode-specific benchmarking framework for the Metro Rail system was developed based on global and Indian practices and prevailing policies. The hierarchy of the benchmarking framework, with goals, criteria and subcriteria, is presented in Fig. 1.

In addition to the above hierarchy, every evaluator comprises formulations which are presented in the section "Integrated and Sustainable Benchmarking of Metro Rail System" of this paper. These are the actual components which assess the performance of the system. As formulations comprise data variables, a database was developed through primary and secondary data collection and by requisite analysis. The data variables associated with every evaluator and its units are presented in Table 1.

\section{Study Methodology}

This paper aims to demonstrate the adopted methodology for benchmarking of a Metro Rail system in an Indian context with a case study of Mumbai. Upon development of the framework, the requisite database was developed through primary and secondary data collection and necessary analysis as discussed above. As the PIs and evaluators structured within a framework exert a non-uniform

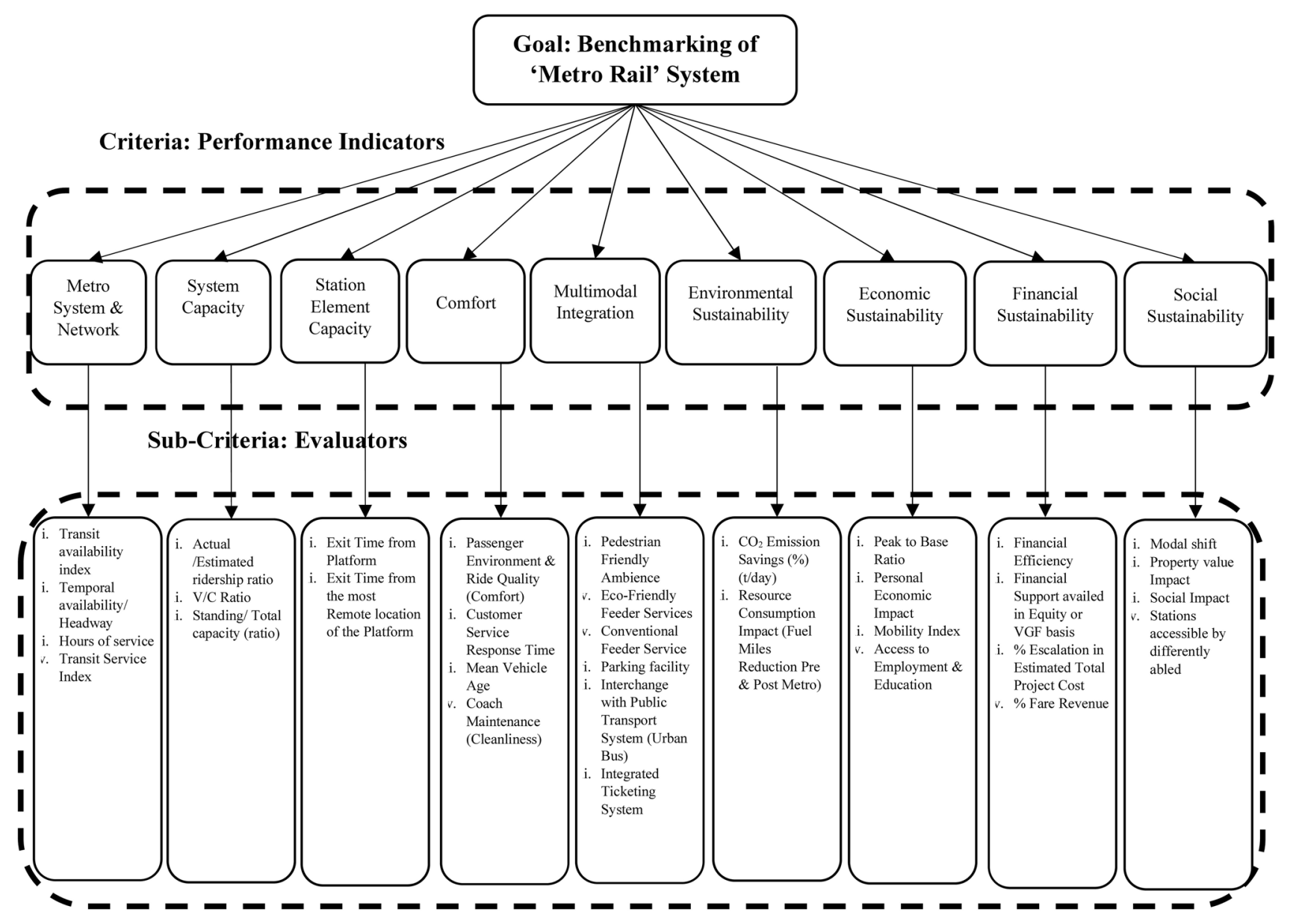

Fig. 1 Hierarchy of proposed integrated and sustainable benchmarking framework for a metro system 
Table 1 Requisite database for integrated and sustainable benchmarking of the Metro Rail system

\begin{tabular}{|c|c|c|c|}
\hline Performance indicators & Evaluators & $\begin{array}{l}\text { Data variables in formulation of } \\
\text { evaluators }\end{array}$ & Units \\
\hline \multirow{6}{*}{$\begin{array}{l}\text { Metro system and network } \\
\text { (MSN) }\end{array}$} & \multirow[t]{2}{*}{ Transit availability index } & Metro stations & No. \\
\hline & & Developed square $\mathrm{km}$ & $\mathrm{km}^{2}$ \\
\hline & Temporal availability/headway & Headway & $\min$ \\
\hline & Hours of service & Hours of service (hours) & $\mathrm{h}: \min$ \\
\hline & Transit Service Index & Travel time by alternate mode (IPT) & $\min$ \\
\hline & (Travel time (min) Savings) & Travel time by transit & $\min$ \\
\hline \multirow[t]{6}{*}{ System capacity (SC) } & \multirow[t]{2}{*}{ Actual/estimated ridership ratio } & Present daily ridership & No \\
\hline & & Estimated ridership & No \\
\hline & \multirow[t]{2}{*}{ V/C Ratio } & Avg. actual passengers/service (pax) & No \\
\hline & & Maximum capacity of service & No \\
\hline & \multirow[t]{2}{*}{ Standing/total capacity (ratio) } & Total capacity of a car & No \\
\hline & & Seating capacity of a car & No \\
\hline \multirow{2}{*}{$\begin{array}{l}\text { Station element capacity } \\
\quad \text { (SEC) }\end{array}$} & Exit time from platform & Exit time from platform & $\min$ \\
\hline & $\begin{array}{l}\text { Exit time from the most remote location of the } \\
\text { platform }\end{array}$ & $\begin{array}{l}\text { Exit time from the most remote location } \\
\text { of the platform }\end{array}$ & $\min$ \\
\hline \multirow[t]{4}{*}{$\begin{array}{l}\text { Comfort and customer } \\
\text { service (CCS) }\end{array}$} & Passenger environment and ride quality & $\begin{array}{l}\text { Passenger environment and ride quality } \\
\text { (comfort) }\end{array}$ & - \\
\hline & Customer service response time & Customer service response time & $\mathrm{s}$ \\
\hline & Mean vehicle age & Mean vehicle age & Years:months \\
\hline & Coach maintenance & Coach maintenance (cleanliness) & - \\
\hline \multirow{6}{*}{$\begin{array}{l}\text { Multimodal integration } \\
\text { (MMI) }\end{array}$} & Pedestrian friendly ambience & Pedestrian friendly ambience & $\%$ \\
\hline & Eco-friendly feeder services & Eco-friendly feeder services & $\%$ \\
\hline & Conventional feeder service & Conventional feeder service & $\%$ \\
\hline & Parking/dropping facility & Parking/dropping facility & $\%$ \\
\hline & Interchange with public transport system & $\begin{array}{l}\text { Interchange with public transport system } \\
\text { (bus) }\end{array}$ & $\%$ \\
\hline & Integrated ticketing system & Integrated ticketing system & $\%$ \\
\hline \multirow{4}{*}{$\begin{array}{l}\text { Environmental } \\
\quad \text { sustainability (ES) }\end{array}$} & \multirow[t]{2}{*}{$\mathrm{CO}_{2}$ emission savings $(\%)$ (t/day) } & Post-metro $\mathrm{CO}_{2}$ emissions/day & t/day \\
\hline & & Pre-metro $\mathrm{CO}_{2}$ emissions/day & t/day \\
\hline & \multirow[t]{2}{*}{$\begin{array}{l}\text { Resource consumption impact (fuel miles reduction } \\
\text { pre and post metro) }\end{array}$} & Post-metro fuel km/day & $\begin{array}{l}\text { million } \\
\mathrm{km} / \mathrm{day}\end{array}$ \\
\hline & & Pre-metro fuel km/day & $\begin{array}{l}\text { million } \\
\mathrm{km} / \mathrm{day}\end{array}$ \\
\hline \multirow{7}{*}{$\begin{array}{l}\text { Economic sustainability } \\
(\text { Ec.S })\end{array}$} & Peak to base ratio & Present daily ridership & No \\
\hline & (Peak hour factor) & Peak hour ridership & No \\
\hline & Personal economic impact & Commuting exp. on metro & INR/trip \\
\hline & (\% Savings per trip using metro system) & Commuting exp. on Pvt. mode & INR/trip \\
\hline & Mobility Index & Average trip length & $\mathrm{km}$ \\
\hline & (Average trip length) & $\begin{array}{l}\text { Length of the corridor } \\
\text { (until last station) }\end{array}$ & $\mathrm{km}$ \\
\hline & Access to employment and education & Work and educational trips & $\%$ \\
\hline \multirow[t]{7}{*}{ Financial sustainability } & \multirow[t]{3}{*}{ Financial efficiency (in INR crores) } & Total annual revenue (fare and non-fare) & INR \\
\hline & & Annual operation cost & INR \\
\hline & & Loan repayment & INR \\
\hline & \multirow[t]{2}{*}{$\begin{array}{l}\text { Financial support availed in equity or VGF basis (no } \\
\text { need to repay) }\end{array}$} & $\begin{array}{l}\text { Financial support availed in equity or } \\
\text { VGF basis }\end{array}$ & INR \\
\hline & & Total project completion cost (TPCC) & INR \\
\hline & $\%$ Escalation in estimated total project cost & Estimated TPC & INR \\
\hline & $\%$ Fare revenue (in INR crores) & Annual fare revenue & INR \\
\hline
\end{tabular}


Table 1 continued

\begin{tabular}{|c|c|c|c|}
\hline Performance indicators & Evaluators & $\begin{array}{l}\text { Data variables in formulation of } \\
\text { evaluators }\end{array}$ & Units \\
\hline \multirow{7}{*}{ Social sustainability } & & Total annual revenue earned & INR \\
\hline & Model shift & $\begin{array}{l}\text { Mode shift from personal transport and } \\
\text { IPT modes }\end{array}$ & $\%$ \\
\hline & \multirow[t]{2}{*}{ Property value impact } & $\begin{array}{l}\% \text { Property appreciation along metro } \\
\text { corridor }\end{array}$ & $\%$ \\
\hline & & $\begin{array}{l}\% \text { Property appreciation beyond metro } \\
\text { corridor }\end{array}$ & $\%$ \\
\hline & \multirow[t]{2}{*}{ Social impact } & Individuals benefited & No \\
\hline & & Individuals affected & No \\
\hline & Stations accessible by differently abled & $\begin{array}{l}\text { Stations accessible by physically } \\
\text { challenged }\end{array}$ & No \\
\hline
\end{tabular}

significance and influence over the overall performance of the Metro Rail system, a priority-based weighing system was developed through expert opinion and incorporated into the benchmarking process in parallel, as shown in Fig. 2. As the expert opinion is subjective in nature, suitable multi-criteria decision making (MCDM) techniques such as the analytic hierarchy process (AHP) and direct weighting were applied for developing a foolproof prioritybased weighing system. Further, the benchmarking was carried out and an overall quality of service (OQoS) for the Mumbai Metro Rail system was determined.

The present study is an absolute benchmarking which measures the performance of various evaluators against a defined standard/scale termed Evaluator Quality of Service (EQoS). As this process is expected to have some vagueness, which we attempted to neutralize through application of the fuzzy logic approach. By these means, Overall Neutralized Rate of Performance (ONRoP) was determined, which is a final metric defining the system's performance. The sequential process adopted in benchmarking the Metro Rail system in the current study is presented in Fig. 2.

\section{Review of MCDM Techniques}

Multi-criteria decision-making (MCDM) techniques are extensively practiced in transportation planning process; selected works dealing with the similar objectives of public transport assessment are discussed in this section. Stefano de Luca [33] applied AHP through public participation for strategic transport planning for the province of Salerno, southern Italy. Different criteria and sub-criteria were considered, and reciprocal weights were calibrated using Saaty's scale of pairwise comparison. Each respondent's opinion was collected through a stated preference survey with two scenarios, i.e. with and without options to improve the transport scenario. It was observed that the magnitude of weights remained the same in both the scenarios with different weights. Also, Lee and Chan [34] engaged AHP through group decision making to assess the urban renewal proposals of Hong Kong and to prioritize the proposals conforming to the interests of the majority. Three major objectives (criteria) with 18 design criteria (sub-criteria) were defined for producing sustainable

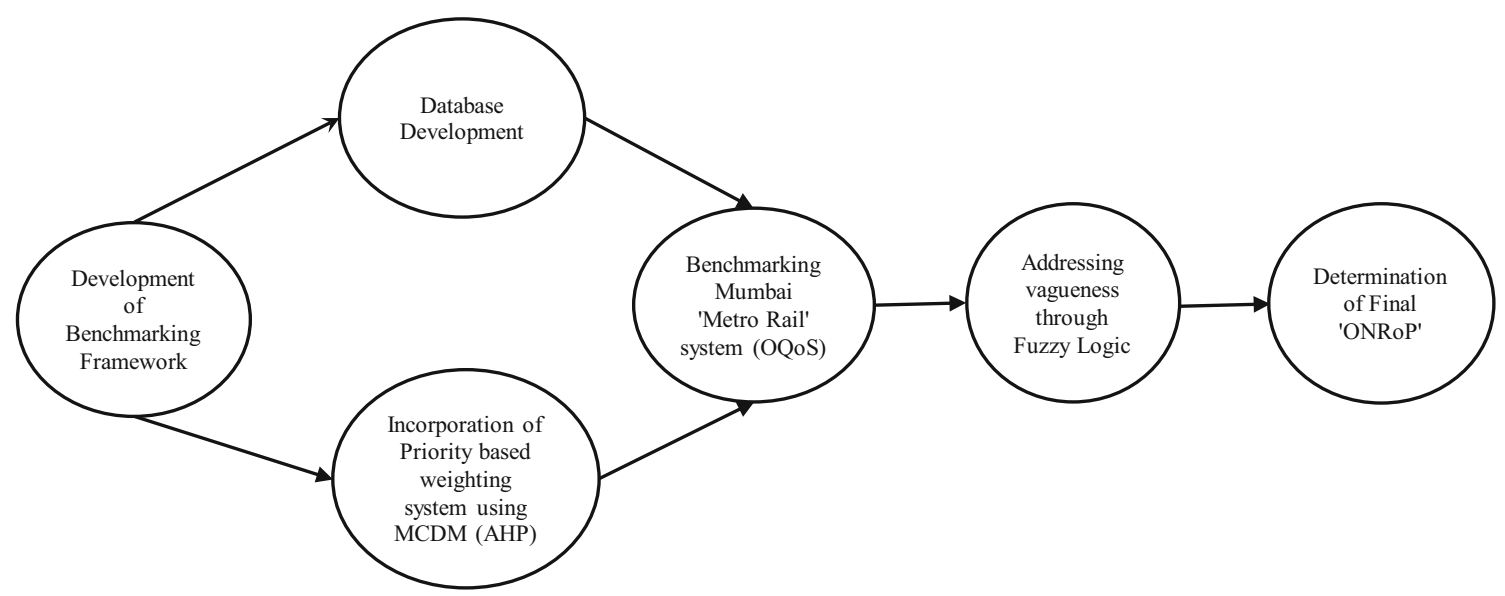

Fig. 2 Methodology for benchmarking of Metro Rail system 
urban renewal proposals. Forty experts were divided into two groups, one with the experts and practitioners working in construction industry and the other with local scholars and people working in non-government organizations (NGOs). Finally, a decision model (framework) was developed with aggregated absolute weights (priorities) equal to 1. Khasnabis and Chaudhry [35] also exercised AHP in ranking transit privatization projects and then compared against the rankings obtained through traditional scoring and scaling techniques. AHP was observed to be a viable technique in prioritizing various transportation projects. Apart from AHP, Huang et al. [36] engaged Technique for Order of Preference by Similarity to Ideal Solution (TOPSIS), a MCDM technique to evaluate the urban rail transit system's performance from the operator's, passenger's and government's perspectives, with eight indicators and 41 sub-indicators. The weight of each sub-indicator was calculated using the entropy weight method (EWM). This approach was demonstrated with a case study on Chengdu subway, Sichuan Province, China.

From the literature, it was also observed that the quality centric assessment studies applied multi-criteria and fuzzy logic approaches to address the subjective nature of the variables and to strengthen the results. Adding strength to this observation, Vaidya [37] and Patrick and Mulley [38] adopted data envelopment analysis (DEA) to evaluate the performance of bus and metro systems, respectively. Further, the authors have adopted AHP and partial factor productivity (PFP) in combination with DEA. Similarly, Kanuganti et al. [39], calculated overall level of service $(\mathrm{LoS})$ rating for public transit routes in the Indian city of Jaipur using different MCDM approaches such as numerical rating, fuzzy set theory, AHP and fuzzy-AHP, and found that fuzzy-set theory and fuzzy-AHP approaches performed better, as they annihilate fuzziness.

Though there are extensive applications of MCDM and fuzzy-AHP techniques in assessing transit performance, the current study engages these techniques independently. MCDM techniques (AHP and direct weighting) were engaged for developing a priority-based weighting system in the pre-benchmarking stage, whereas the fuzzy logic approach was engaged to address the vagueness in scaling/ranking in the post-benchmarking stage, which is novel.

\section{Determination of Weights by Expert Opinion Survey}

As discussed earlier, the indicators and evaluators were expected to have a distinctive influence on the metro system performance, hence they could not be weighted uniformly. Further, the perception of the significance and weight of such indicators and evaluators varies from person to person as these are subjective judgments. Hence, an expert opinion was collected by AHP and direct weighting methods for determining the weights of PIs and evaluators, respectively. Several experts, such as industry practitioners, professionals working in PTAs, academicians and young researchers working in the discipline of urban transport with a better than average understanding of public transport and associated polices in the Indian context, were chosen for the expert opinion survey. Experience of the participating experts in this opinion survey ranged from $3+$ to 25+ years, ensuring a blend of experience and ingenuity.

AHP was chosen over other MCDM methods because of its convenience towards pairwise comparisons, ability to check inconsistencies and its intuitive appeal to the decision makers. Further, AHP also supports group decision making [40].

Direct weighting was chosen for determination of evaluator weights, due to the complexity of handling $600+$ exhaustive pairwise comparisons for 34 evaluators in AHP. Further, evaluators being a micro-level aspect in such a comprehensive framework, direct weighting within a PI group should suffice. Detailed procedures adopted for obtaining opinion/decision through AHP and direct weighting methods are presented in the following subsections.

\subsection{Determination of Priority-Based PI Weights by the AHP Method}

In AHP, the decision maker (the expert in this case) assigns his priority in a pairwise comparison among the available alternatives. In the present case, the pairwise ranking is collected for nine PI groups from the experts on the Scale of Relative significance proposed by Saaty [41], as shown in Table 2.

Accordingly, the opinions received from the experts were considered as a judgment matrix or a decision matrix. One such judgment is shown in Table 3. After obtaining the judgment matrix, its consistency was also assessed as proposed by Saaty [42].

After obtaining the judgment matrix, the normalized relative weight was derived. Further, the normalized principal eigenvector was obtained by averaging across the rows; this is also called a priority vector. The priority vector shows relative weights among the PI groups being compared as shown in Table 4.

To assess the consistency of the expert opinion, the principal eigenvalue $\left(\lambda_{\max }\right)$ was obtained from the summation of products between each element of eigenvector and the sum of columns of the judgment matrix as shown in Table 4. 
Table 2 Illustrative criterion matrix for pairwise comparison using AHP. Source: Saaty [41]

\begin{tabular}{lll}
\hline Intensity of importance & Definition & Explanation \\
\hline 1 & $\begin{array}{l}\text { Equal significance } \\
\text { Relative significance of one over } \\
\text { another } \\
\text { Moderate significance of one over } \\
\text { another }\end{array}$ & $\begin{array}{l}\text { Two IGs contribute equally to the objective } \\
\text { Experience and judgment relatively favour one PI over another }\end{array}$ \\
5 & $\begin{array}{l}\text { Strong significance } \\
\text { Extreme significance }\end{array}$ & $\begin{array}{l}\text { An PI is strongly favoured and its dominance demonstrated in practice } \\
\text { The evidence favouring one activity over another is of the highest possible } \\
\text { order of affirmation }\end{array}$ \\
$\begin{array}{l}\text { Intermediate values between the two adjacent judgments } \\
\text { Reciprocals of above } \\
\text { nonzero }\end{array}$ & $\begin{array}{l}\text { If, for a given criterion, option A has a rating of one of the above when compared to option B, then option B has the } \\
\text { reciprocal rating when compared to option A }\end{array}$ \\
\hline
\end{tabular}

Table 3 Judgment matrix of an expert for PIs in AHP

\begin{tabular}{lccllllllc}
\hline PIs & MSN & SC & SEC & CCS & MMI & ES & Ec.S & FS & SS \\
\hline MSN & 1 & 1 & $1 / 3$ & 3 & $1 / 3$ & $1 / 3$ & 1 & 1 & $1 / 3$ \\
SC & 1 & 1 & $1 / 3$ & 3 & $1 / 3$ & 1 & 1 & 1 & 1 \\
SEC & 3 & 3 & 1 & 5 & 1 & 1 & 1 & 1 & 1 \\
CCS & $1 / 3$ & $1 / 3$ & $1 / 5$ & 1 & $1 / 5$ & $1 / 3$ & $1 / 3$ & $1 / 5$ & $1 / 3$ \\
MMI & 3 & 3 & 1 & 5 & 1 & 3 & 3 & 1 & 1 \\
ES & 3 & 1 & 1 & 3 & $1 / 3$ & 1 & $1 / 3$ & 1 & 1 \\
Ec.S & 1 & 1 & 1 & 3 & $1 / 3$ & 3 & 1 & 3 & 3 \\
FS & 1 & 1 & 1 & 5 & 1 & 1 & $1 / 3$ & 1 & 3 \\
SS & 3 & 1 & 1 & 3 & 1 & 1 & $1 / 3$ & $1 / 3$ & 1 \\
SUM & 16.33 & 12.33 & 6.87 & 31.00 & 5.53 & 11.67 & 8.33 & 9.53 & 11.67 \\
\hline
\end{tabular}

Next, using $\lambda_{\max }$, the Consistency Index (CI) was determined by using Eq. 1 as proposed by Saaty [42].

$\mathrm{CI}=\frac{\lambda_{\max }-n}{n-1}=\frac{9.95-9}{9-1}=\mathbf{0 . 1 1 8}$

$n=$ number of alternatives, PI groups in this case.
The CI was then compared with the average CI of randomly generated reciprocal matrices (judgment matrices) or random consistency index (RI). The average random consistency index of a sample size of 500 matrices is shown in Table 5, as proposed by Saaty [42].

Saaty [42] proposed a consistency ratio (CR), which is a ratio between $\mathrm{CI}$ and $\mathrm{RI}$ as shown in Eq. 2.

Table 4 Normalized relative weight matrix and priority vector

\begin{tabular}{lllllllllllll}
\hline Performance indicators & MSN & SC & SEC & CCS & MMI & ES & Ec.S & FS & SS & SUM & Priority vector (weights) & $\lambda_{\text {max }}$ \\
\hline MSN & 0.06 & 0.08 & 0.05 & 0.10 & 0.06 & 0.03 & 0.12 & 0.10 & 0.03 & 0.63 & 7.00 & 10.29 \\
SC & 0.06 & 0.08 & 0.05 & 0.10 & 0.06 & 0.09 & 0.12 & 0.10 & 0.09 & 0.74 & 8.27 & 9.18 \\
SEC & 0.18 & 0.24 & 0.15 & 0.16 & 0.18 & 0.09 & 0.12 & 0.10 & 0.09 & 1.31 & 14.57 & 9.92 \\
CCS & 0.02 & 0.03 & 0.03 & 0.03 & 0.04 & 0.03 & 0.04 & 0.02 & 0.03 & 0.26 & 2.92 & 8.16 \\
MMI & 0.18 & 0.24 & 0.15 & 0.16 & 0.18 & 0.26 & 0.36 & 0.10 & 0.09 & 1.72 & 19.14 & 9.53 \\
ES & 0.18 & 0.08 & 0.15 & 0.10 & 0.06 & 0.09 & 0.04 & 0.10 & 0.09 & 0.88 & 9.82 & 10.31 \\
Ec.S & 0.06 & 0.08 & 0.15 & 0.10 & 0.06 & 0.26 & 0.12 & 0.31 & 0.26 & 1.39 & 15.49 & 11.62 \\
FS & 0.06 & 0.08 & 0.15 & 0.16 & 0.18 & 0.09 & 0.04 & 0.10 & 0.26 & 1.12 & 12.42 & 10.66 \\
SS & 0.18 & 0.08 & 0.15 & 0.10 & 0.18 & 0.09 & 0.04 & 0.03 & 0.09 & 0.93 & 10.38 & 10.90 \\
SUM & 1.00 & 1.00 & 1.00 & 1.00 & 1.00 & 1.00 & 1.00 & 1.00 & 1.00 & 9 & 100 & $9.95(\mathrm{avg})$ \\
\hline
\end{tabular}


Table 5 Random consistency index proposed by Saaty. Source: Saaty [42]

\begin{tabular}{lllllllllll}
\hline$n$ & 1 & 2 & 3 & 4 & 5 & 6 & 7 & 8 & 9 & 10 \\
\hline RI & 0 & 0 & 0.58 & 0.90 & 1.12 & 1.24 & 1.32 & 1.41 & 1.45 & 1.49 \\
\hline
\end{tabular}

$\mathrm{CR}=\frac{\mathrm{CI}}{\mathrm{RI}}=\frac{0.118}{1.45}=8.13 \%$

Further, Saaty claimed that an acceptable consistency ration $(\mathrm{CR})$ should be less than $10 \%$; however, a ratio less than $20 \%$ is considered tolerable [43]. Accordingly, only the expert opinions within $20 \% \mathrm{CR}$ were considered as acceptable samples, and the rest were rejected. The CR of the judgment by an expert illustrated above is $8.13 \%$ which is $<20 \%$, hence acceptable.

By following the described procedure, 7 of the 12 expert opinions, i.e. $58.33 \%$ were found to be found to be tolerable and were considered for further analysis. Accordingly, the weights were determined by taking the arithmetic mean of these samples and the final resultant weightages for nine PI groups are shown in Fig. 3.

The experts prioritized the service-oriented PIs Metro System and Network and System Capacity. Further, Social Sustainability was also signified in the same trend. Multimodal Integration was prioritized next to these PI groups. Amongst the other sustainable PIs, Economic Sustainability was prioritized, followed by Environmental Sustainability. Financial Sustainability was placed next in order of priority. Comfort was rated as the PI of least priority.

\subsection{Determination of Evaluator Weights by Direct Weighting Method}

In this method, the experts were requested to offer their judgment/decision for evaluators nested under a PI group in the form of simple numerical weights. The collective sum of all these numerical weights shall be equal to 100 and the offered judgment against these evaluators shall act as their respective weights within the PI group. The resultant weights of these evaluators are shown in Table 6 (Col. 6) as part of benchmarking in the section "Integrated and Sustainable Benchmarking of Metro Rail System".

\section{Integrated and Sustainable Benchmarking of Metro Rail System}

Subsequent to the determination of priority-based weights through expert opinion, the data requirement was identified from the formulations of evaluators which were designed in accordance with the Indian data formats as presented in Table 6 . In addition to the secondary data, primary data

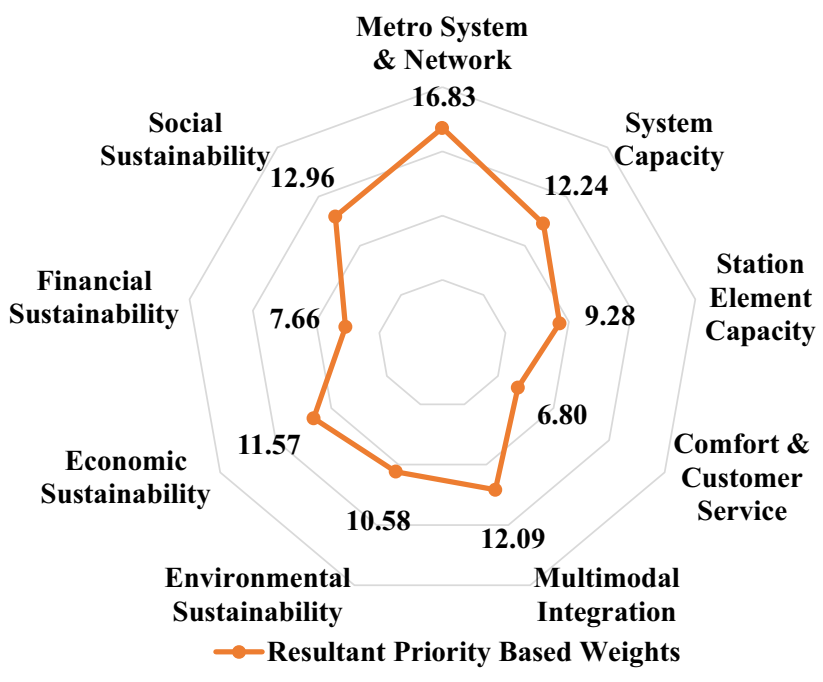

Fig. 3 Resultant priority-based weights of PIs by AHP through expert opinion

were also collected with the help of the Mumbai Metropolitan Region Development Authority (MMRDA) to satisfy the comprehensive framework. The developed framework was exercised on Mumbai Metro Line 1 after completion of the necessary data analysis as discussed earlier. After feeding the data, a trailing procedure was adopted to finally arrive at a conclusion on the overall performance of the system.

Evaluator performances were assessed with respective formulations. An exclusive quality of service was derived based on the output as Evaluator Quality of Service (EQoS) on a scale of 1 to 4 . The respective EQoS achieved by every evaluator is highlighted in Table 6 (Column No. 5).

Further, the PI groups in the framework are also assessed individually and an Indicator Quality of Service (IQoS) was derived using Eq. 3 .

$\mathrm{IQoS}=\sum_{i=1}^{n} \frac{\mathrm{WE} i \times \mathrm{EQoS} \text { of } i}{10}$

WE $i=$ weight of evaluator $i . n$ is the total number of evaluators, here the nuber of evaluators is 34 . EQoS = evaluator quality of service.

For greater convenience and further application in the fuzzy logic approach, the Indicator Rate of Performance (IRoP) is represented using the equation below for an easy resemblance.

$\operatorname{IRoP}(\%)=\left(\frac{\mathrm{IQoS}}{4}\right) \times 100$

Similarly, the Overall Quality of Service (OQoS) for the entire Metro System is represented as below.

$\mathrm{OQoS}=\sum_{i=1}^{n} \frac{\mathrm{WPI} i \times \mathrm{IQoS} i}{400}$ 


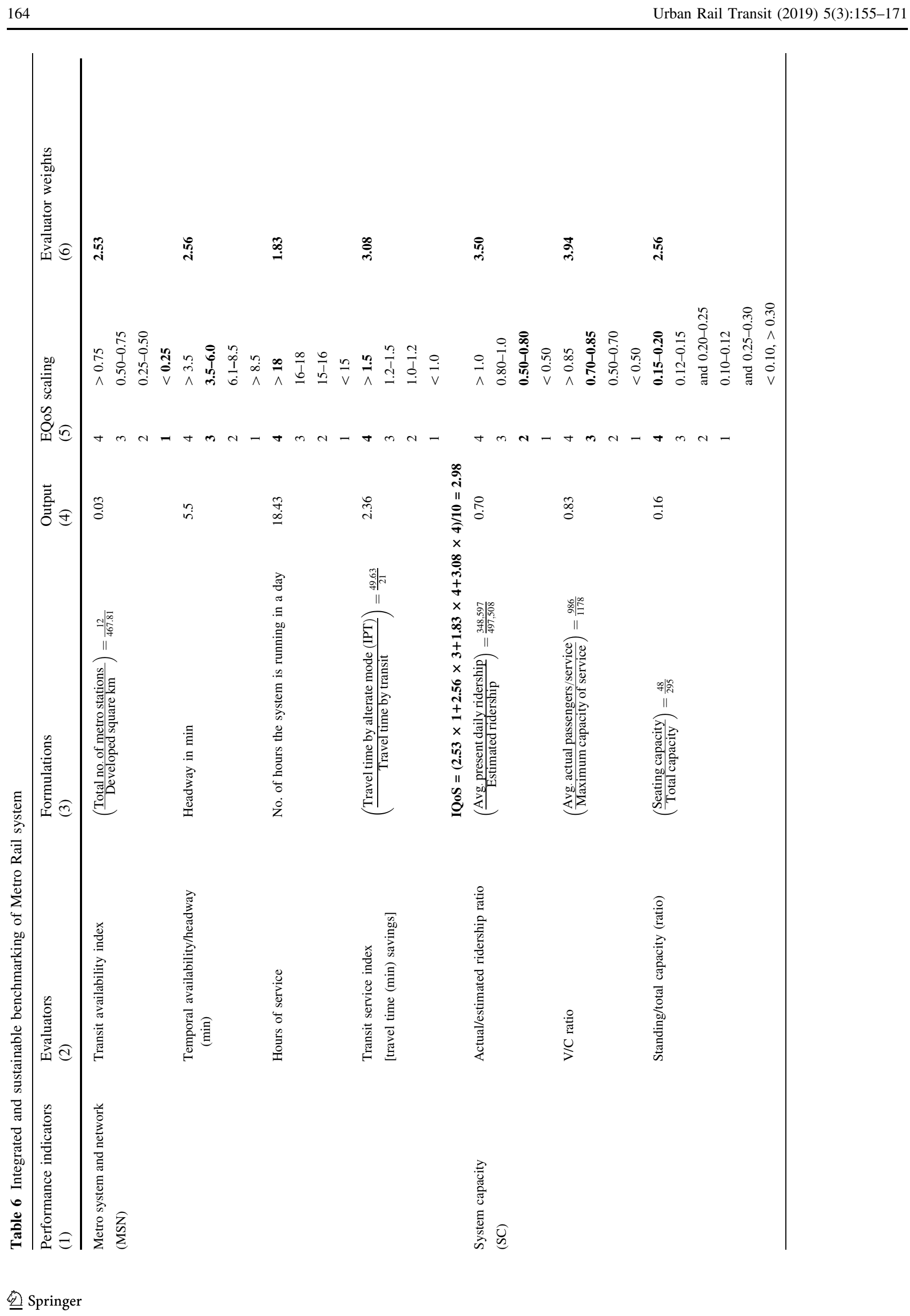




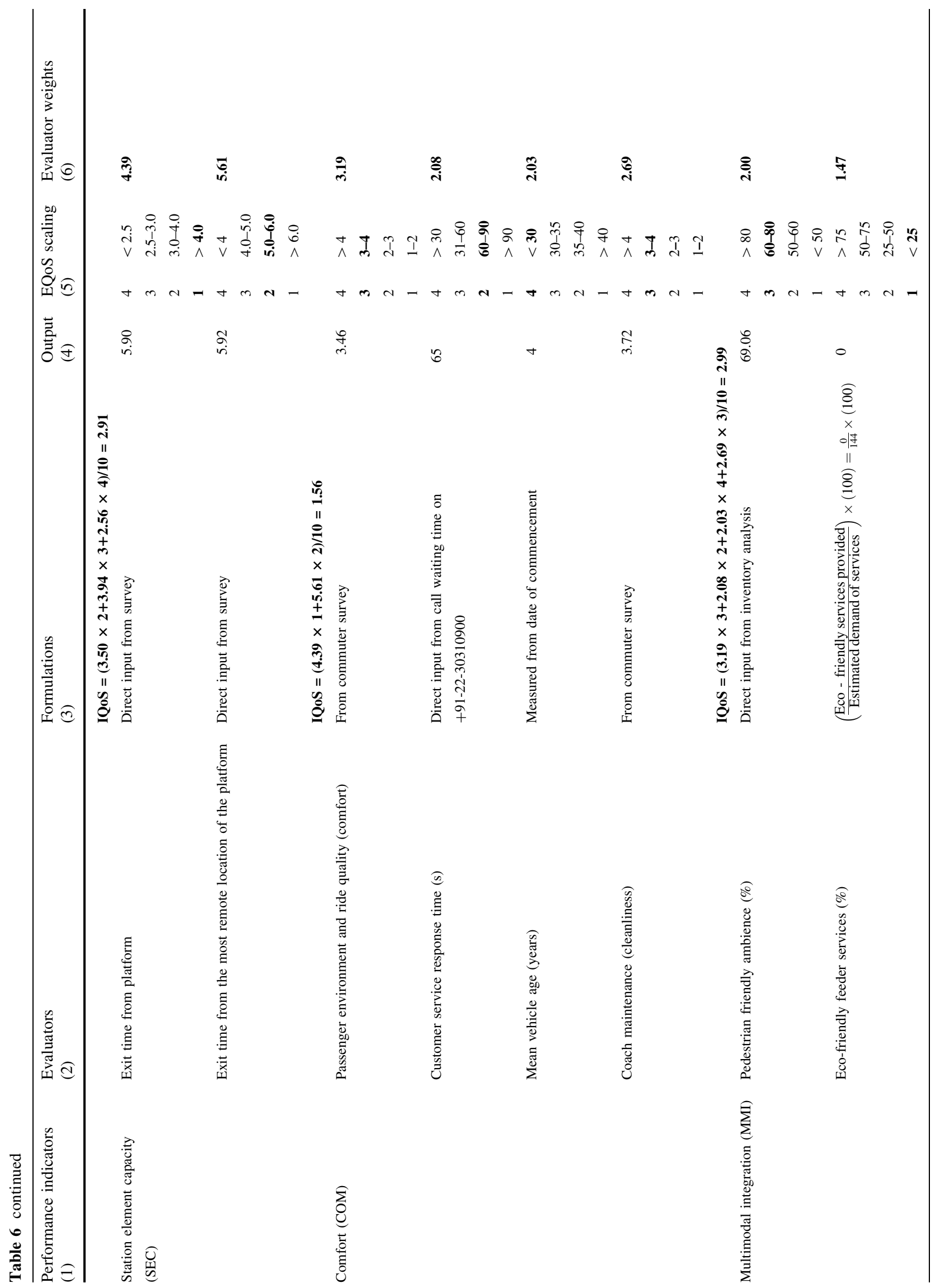




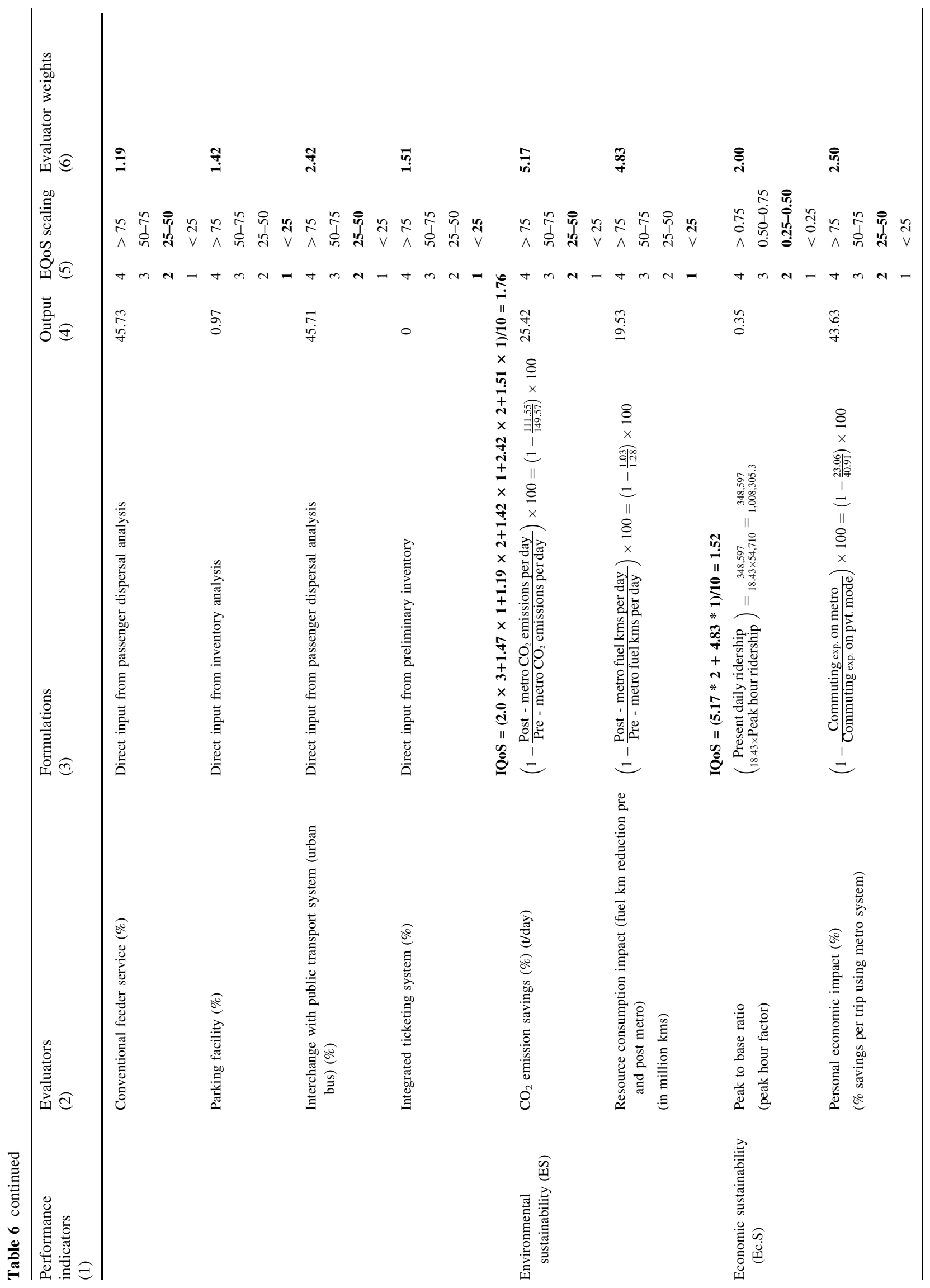




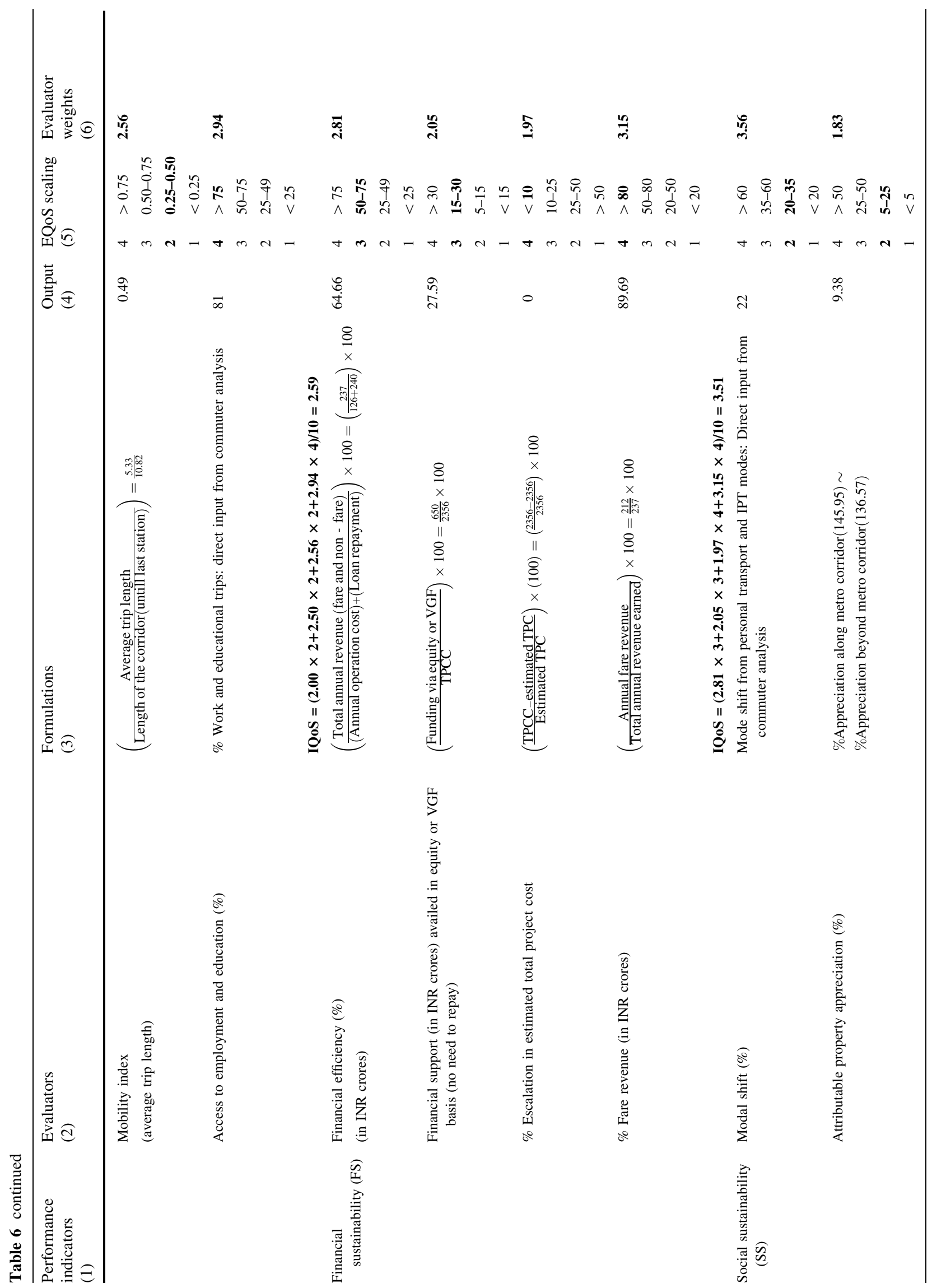




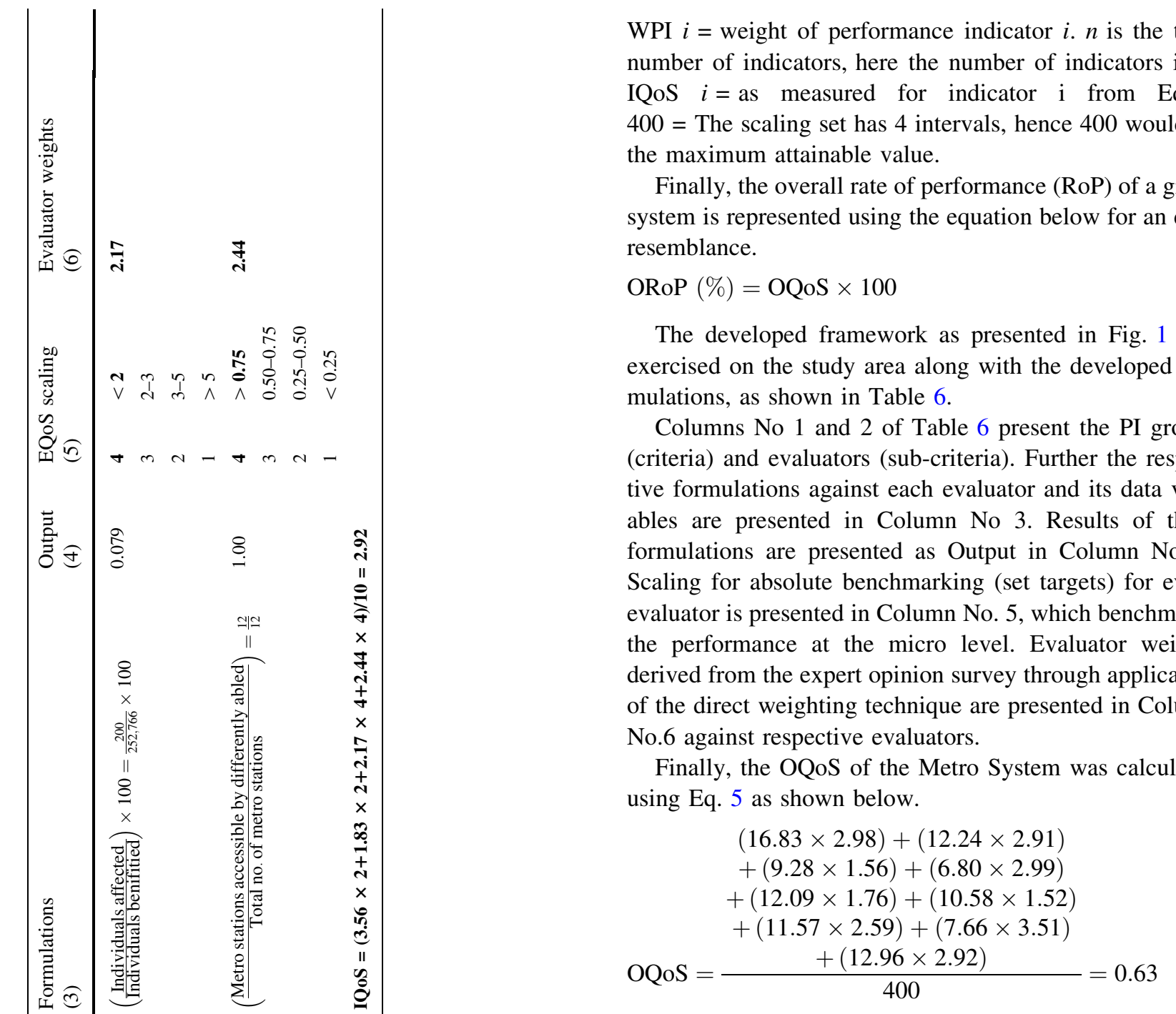

After carrying out this detailed comprehensive data collection and analysis and exercising the developed framework, the Mumbai City's Metro System was found to be performing at a rate of 0.63 on a scale of 0 to 1 . The Rate of Performance (RoP) for the entire system was assessed using Eq. 6 as shown below.

ORoP $(\%)=$ OQoS $\times 100=63.17 \sim 63 \%$

\section{Application of Fuzzy Logic and Linguistic Ratings}

In addition to the application of AHP and direct weighting techniques for logically defining the weights of PIs and evaluators, the associated vagueness in the scaling process of benchmarking was addressed by application of the logic approach using a triangular membership function (TMF).

Defining raking intervals for evaluators and PIs requires knowledge about the interdependencies between the 
Table 7 Linguistic ratings of the benchmarking for IRoP

\begin{tabular}{ll}
\hline IRoP $(\%)$ & Linguistic ratings \\
\hline$<35$ & Poor $(\mathrm{P})$ \\
$35-50$ & Fair $(\mathrm{F})$ \\
$50-70$ & Good $(\mathrm{G})$ \\
$70-90$ & Very good (VG) \\
$>90$ & Very poor (VP) \\
\hline
\end{tabular}

Table 8 Scalar parameters of linguistic variables

\begin{tabular}{|c|c|c|c|c|}
\hline \multirow[t]{2}{*}{ Linguistic variable } & \multicolumn{3}{|c|}{ Scalar parameters } & \multirow{2}{*}{$\begin{array}{l}\text { Defuzzification } \\
\frac{(a+b+c)}{3}\end{array}$} \\
\hline & $a$ & $b$ & $c$ & \\
\hline VG & 0.90 & 1.00 & 1.00 & 0.97 \\
\hline G & 0.75 & 0.90 & 1.00 & 0.88 \\
\hline $\mathrm{F}$ & 0.50 & 0.75 & 0.90 & 0.72 \\
\hline $\mathrm{P}$ & 0.35 & 0.50 & 0.75 & 0.53 \\
\hline VP & 0.10 & 0.35 & 0.50 & 0.32 \\
\hline
\end{tabular}

system performance measures and the corresponding PIs. Due to the complexity of such a qualitative subject, the data required for assessment are sometimes vague and ambiguous. In such situations, fuzzy logic facilitates a mathematical approach to blend the best of available knowledge and counterpoise the vagueness within the ranking system. The IRoP is categorized on a scale of 1 to 5 using linguistic ratings as shown in the Table 7. Since these ratings are perceptive and qualitative in nature, they were normalized to avoid any uncertainty and vagueness in the benchmarking using fuzzy logic membership functions.

The scalar parameters of the linguistic variables were defined based on the realistic scenario of metro systems in India, as shown in Table 8.

The defuzzied value achieved for respective Linguistic Variable was assigned to respective PI and the overall normalized rate of performance (ONRoP) was calculated as shown in Table 9.

After application of the fuzzy logic approach using the triangular membership function and defuzzification, the overall normalized rate of performance of Mumbai's Metro System was computed as $75.22 \%$ (say $75 \%$ ).

\section{Conclusions and Discussion}

Fast track implementation of $700 \mathrm{~km}$ of Metro Rail network [44] in conjunction with lack of institutionalized benchmarking techniques and prioritization tools motivated this study towards development of a mode-specific framework for the Indian context with nine PIs and 34 evaluators. A priority-based weighting system was incorporated in the proposed benchmarking framework through expert opinion with application of MCDM techniques such as AHP and direct weighting. This application strengthened the framework with participation of several industry and academic experts including those associated with public transport agencies.

The study reveals that Mumbai's Metro network is outperforming to a satisfactory level in service and qualityoriented sectors such as Metro System Network, System Capacity and Comfort. The Multimodal Integration aspect of the system has a huge scope of improvement in the areas of facilitating requisite feeder services, parking facilities and integrated ticketing system. The and Station Element Capacity is no good due to its poor performance during peak hours. Though the social aspect of the Sustainability dimension is performing at a satisfactory level, the rest of the aspects such as environment, economic and financial PIs, need significant improvement in the areas of ambient air and noise quality, out-of-pocket savings to the

Table 9 Performance ratings after defuzzification

\begin{tabular}{lllllc}
\hline Performance indicators & IQoS & IRoP $(\%)$ & Linguistic rating & $\begin{array}{l}\text { Defuzzified value } \\
\text { (DV) } \\
\text { (Table 8) }\end{array}$ & $\begin{array}{l}\text { Indicator weights } \\
\text { (WPI) }\end{array}$ \\
\hline Metro system and network & & & & 0.88 & 16.83 \\
System capacity & 2.98 & 74.61 & $\mathrm{G}$ & 0.88 & 12.24 \\
Station element capacity & 2.91 & 72.64 & $\mathrm{G}$ & 0.53 & 9.28 \\
Comfort & 1.56 & 39.03 & $\mathrm{P}$ & 0.88 & 6.80 \\
Multimodal integration & 2.99 & 74.86 & $\mathrm{G}$ & 0.53 & 12.09 \\
Environmental sustainability & 1.76 & 44.01 & $\mathrm{P}$ & 0.53 & 10.58 \\
Economic sustainability & 1.52 & 37.93 & $\mathrm{P}$ & 0.72 & 11.57 \\
Financial sustainability & 2.59 & 64.72 & $\mathrm{~F}$ & 0.88 & 7.66 \\
Social sustainability & 3.51 & 87.83 & $\mathrm{G}$ & $\mathrm{G}$ & 0.88 \\
Overall normalized rate of performance $(\mathbf{O N R o P})=\mathbf{W P I} \times \mathbf{D V}$ & & & 75.22 \\
\hline
\end{tabular}


commuter, mobility index etc. To conclude, Mumbai's Metro System is performing at an ORoP of $63 \%$.

Fuzzy logic application had improved the results by neutralizing the vagueness associated within the scaling/ ranking system resulting in an ONRoP of $75 \%$. Hence, engagement of MCDM techniques and fuzzy Logic in preand post-benchmarking stages, respectively, improved the results of benchmarking. This novel methodology may be adopted for similar framework-based benchmarking practices.

Further, as substantial funding for development of Metro Rail systems is being sought through multilateral and bilateral funding agencies, prompt repayment of these loans is a huge responsibility on the Government. Hence, wise allocation and prioritization of available funds for various public transport projects plays a key role in achieving broader sustainability at the national level. To achieve this, the developed framework may be institutionalized and exercised at regular intervals to track and compare the performance of various Metro Rail systems in India. In addition, the developed framework may also be utilized to benchmark the planned Metro Rail projects with minimal customization to have a comparative statement of the anticipated performance of these projects under review. This exercise can act as a substitute to the Alternative Analysis proposed in the Metro Rail Policy-2017 in the Indian context.

Acknowledgements The authors thank the management of Mumbai Metropolitan Region Development Authority (MMRDA) for sharing the requisite data towards benchmarking of Metro System in Mumbai.

Open Access This article is distributed under the terms of the Creative Commons Attribution-NonCommercial 4.0 International License (http://creativecommons.org/licenses/by-nc/4.0/), which permits any noncommercial use, distribution, and reproduction in any medium, provided you give appropriate credit to the original author(s) and the source, provide a link to the Creative Commons license, and indicate if changes were made.

\section{References}

1. MoRTH (2016) Government of India, steps taken to improve public transport in cities. http://pib.nic.in/newsite/mbErel. aspx? relid=147463. Accessed 4 Aug 2019

2. MMRDA (2008) "Final report-executive summary of comprehensive transportation study" for Mumbai Metropolitan Region. MMRDA, Mumbai

3. MRVC (2018) Overview of the existing Mumbai suburban railway. http://www.mrvc.indianrailways.gov.in/view_section. jsp?lang $=0$ \&id $=0,294,302$

4. MMRDA (2017) Basic transport and communications statistics for Mumbai Metropolitan Region. MMRDA, Mumbai

5. MMRDA, PIU (2018) Mumbai metro master plan. https://mmrda. maharashtra.gov.in/metro-piu. Accessed 4 Aug 2019

6. MoUD (2010) Service level benchmarks for urban transport at a glance. SLB for Urban Transport-Government of India
7. MoUD and CEPT (2013) Service level benchmarking in urban transport for Indian cities

8. MoUD (2014) National urban transport policy, 2014. Government of India

9. MoHUA (2017) Appraisal guidelines for metro rail project proposals. Government of India

10. MoHUA (2017) Metro rail policy, 2017. Government of India

11. Transportation Research Board (TRB) (2003) A guidebook for developing a transit performance measurement system. Transit Cooperative Research Program, Report 88

12. Transportation Research Board of the National Academies (2013) TCRP report 165: Tran-sit capacity and quality of service manual, third edition. Transportation Research Board, Washington, D.C.

13. National Center for Transit Research (NCTR) (2004) Benchmark rankings for transit systems in the United States. State of Florida, Department of Transportation, Technical report no. NCTR-52703

14. Paz A, Maheshwari P, Kachroo P, Ahmad S (2013) Estimation of performance indices for the planning of sustainable transportation systems. Adv Fuzzy Syst. https://doi.org/10.1155/2013/601468

15. Alter CH (1976) Evaluation of public transit services: the levelof-service concept. Transp Res Rec 606:37-40

16. Balachandra P, Reddy BS (2013) Benchmarking Bangalore city for sustainability - an indicator-based approach. The Center for Infrastructure, Sustainable Transportation and Urban Planning, Indian Institute of Science, Bangalore

17. Bickford G (2013) Literature review on public transport and mobility in municipalities. S Afr Cities Netw 2:2013

18. Buehler R, Pucher J (2011) Making public transport financially sustainable. Transp Policy 18:126-138

19. Bongardt D, Schmid D, Huizenga C, Litman T (2011) Sustainable transport evaluation: developing practical tools for evaluation in the context of the CSD process. Deutsche Gesellschaft für Internationale Zusammenarbeit (GIZ) GmbH, Federal Ministry for the Environment, Germany and Federal Environmental Agency, Germany Sustainable Urban Transport Technical Document \#7

20. Bruun E, Vanderschuren M (2017) Assessment methods from around the world potentially useful for public transport projects. J Public Transp 20(2):6

21. Fu L, Xin Y (2007) A new performance index for evaluating transit quality of service. J Public Transp 10(3):4

22. Martens K (2015) Accessibility and potential mobility as a guide for policy action. Transp Res Rec 2499:18-24

23. Kittelson \& Associates, Inc. et al. (2003) A guidebook for developing a transit performance-measurement system. TCRP report 88, National Academy Press, Washington, D.C.

24. Eboli L, Mazzulla G (2011) Performance indicators for an objective measure of public transport service quality. European TransportlTrasporti Europei, Issue 51, Paper no. 3. ISSN 1825-3997

25. Jasti PC, Ram VV (2016) Integrated and sustainable service level benchmarking of urban bus system. Transp Res Procedia 17(2016):301-310

26. Jasti PC, Ram VV (2018) Integrated performance assessment and service level benchmarking of urban bus system using fuzzy logic. European TransportlTrasporti Europei, Issue 69, Paper no. 1. ISSN 1825-3997

27. Mishra S, Welch TF, Jha MK (2012) Performance indicators for public transit connectivity in multi-modal transportation networks. Transp Res Part A Policy Practice 46(7):1066-1085

28. Derrible S, Kennedy C (2010) Evaluating, comparing, and improving metro networks, application to plans for Toronto, Canada. J Transp Res Board. https://doi.org/10.3141/2146-06 
29. Litman T (2014) Well measured: developing indicators for sustainable and livable transport planning. Victoria Transport Policy Institute. www.vtpi.org. Accessed May 2014

30. Litman T (2003) Measuring transportation: traffic, mobility and accessibility. ITE J 73(10):28-32

31. National Fire Protection Association (NFPA) (2017) 130, Standard for fixed guideway transit and passenger rail systems

32. MoUD (2013) Report of the sub-committee on rolling stock for metro railways. Government of India

33. Stefano de Luca (2014) Public engagement in strategic transportation planning: an analytic hierarchy process based approach. Transp Policy 33(2014):110-124

34. Lee GK, Chan EH (2008) The analytic hierarchy process (AHP) approach for assessment of urban renewal proposals. Soc Indic Res 89(1):155-168

35. Khasnabis S, Chaudhry BB (1994) Prioritizing transit markets using analytic hierarchy process. J Transp Eng 120(1):74-93

36. Huang W, Shuai B, Sun Y, Wang Y, Antwi E (2018) Public engagement in strategic transportation planning: an analytic hierarchy process based approach using entropy-TOPSIS method to evaluate urban rail transit system operation performance: The China case. Transp Res Part A 111(2018):292-303
37. Vaidya OS (2014) Evaluating the performance of public urban transportation systems in India. J Public Transp 17(4):2014

38. Patrick C-HT, Mulley C (2013) Benchmarking the efficiency performance of international metro systems. In: Proceedings of the Eastern Asia society for transportation studies, vol 9. Sydney

39. Kanuganti S, Subramanian U, Arkatkar SS, Singh AP, Sarkar AK (2013) Quantification of level-of-service index for bus routes in developing countries: a case study in India. J East Asia Soc Transp Stud 10:1347-1366

40. Gavade RK (2014) Multi-criteria decision making: an overview of different selection problems and methods. Int J Comput Sci Inf Technol 5(4):5643-5646

41. Saaty TL (1977) A scaling method for priorities in hierarchical structures. J Math Psychol 15(3):234-281

42. Saaty TL (1980) The analytic hirereachy process. McGraw Hill, New York

43. Wedley WC (1993) Consistency prediction for incomplete AHP matrices. Math Comput Modell 17(4/5):151-161

44. MoHUA (2018) Annual report 2017-2018. Government of India 